\title{
13 Managing energy and climate transitions in theory and practice
}

\author{
A critical systematic review of \\ Strategic Niche Management
}

Kirsten E.H. Jenkins and Benjamin K. Sovacool

\section{Introduction}

Ambitious goals for reducing carbon emissions require a rapid and extensive deployment of low-carbon technologies throughout the economy, with farreaching implications for infrastructures, institutions, social practices and cultural norms. As the International Renewable Energy Agency (IREA) and International Energy Agency (IEA) (2017) recently noted, meeting the goals enshrined in the Paris Agreement - limiting global temperature rise to below $2^{\circ} \mathrm{C}$ above pre-industrial levels - demands we reduce the carbon dioxide intensity of the global economy by 85 per cent in 35 years. This corresponds to an average reduction of energy-related carbon dioxide emissions of about 2.6 per cent per year, or 0.6 Gigatons per year (IREA and IEA, 2017).

Meeting such targets will necessitate low-carbon transitions across multiple sociotechnical domains, namely electricity and heat, industry and buildings, forestry and agriculture, and transport, to name a few (Geels et al., 2017). Yet, so far, progress on global energy and climate policy has been phlegmatic, and the pace of change is set to become ever more lethargic in the wake of the Trump Administration's plans to reinvest in carbon-intensive forms of energy such as tar-sands, oil and natural gas, and coal. Admittedly, the rate and scale of this transformative change has few historical precedents and represents a major policy challenge (Sovacool, 2016).

Transitions frameworks for understanding the pathways by which these changes occur have emerged in response to universal and localised energy challenges, including the coupled threats of climate change, fossil fuel depletion and fuel poverty. This chapter focuses on new technological innovation, the destabilisation of dominant energy regimes and the reframing of transitions goals through one such framework: Strategic Niche Management (SNM) (Markard et al., 2012; Schot and Steinmuller, 2016). SNM promotes 'the reflexive management of realworld experiments in the form of pilot and demonstration projects, in which new sociotechnical configurations can grow and conditions for their 'up-scaling' can be elaborated"' (van den Bergh et al., 2011, p. 13). In essence, SNM offers a means of learning about and enhancing the development and diffusion of new technologies with the aim of meeting low-carbon and low-energy goals. 
Since the articulation and development of the SNM field by the end of the 1990s (Kemp et al., 1998; Weber et al., 1999), applications have increased steadily, gaining particular traction with energy scholars. Articles have been published with regards to electricity production and use with a focus on biomass (Raven, 2005; van der Laak et al., 2007; Verbong et al., 2010), zero energy buildings (Jain et al., 2016; Martiskainen and Kivimaa, 2018), clean vehicles (Hoogma et al., 2002; Sushandoyo and Magnusson, 2014) and the role of actors (Caniëls and Romijn, 2008; Lovell, 2007) among others. As a further example, Sovacool (2017) surveyed social science theorists about conceptual approaches for transitions in the transport sector to electric mobility, where both SNM and sociotechnical transitions theory were prominently discussed.

In this chapter, we provide an updated, confirmatory analysis of the ten-year literature review of the SNM literature provided by Schot and Geels (2008). Moreover, we present a synthesis of lessons learnt for both academic studies and policymakers working towards low-energy transitions. Specifically, we ask: what insights do 15 years of SNM literature offer for how to manage, or accelerate, lowcarbon energy transitions? Arranz (2017) notes in a meta-survey of the sociotechnical transitions field the need for more refined understanding of what it takes to drive energy transitions - a progress typically undertaken by looking at past transitions (Grubler et al., 2016). This chapter makes another important step towards this goal through its focus on forward-looking policy recommendations.

We begin with a brief overview of the SNM heuristic, necessary to contextualise the results that follow. We then present the methodology behind our systematic review and content analysis covering 15 years of SNM literature (between 2002 and 2016) published across 9 databases, as well as 22 newsletters developed by the Sustainability Transitions Research Network (STRN). This approach allows for the identification of emergent research themes, as well as data about authors, their methods, and case studies in addition to analytical strategies and proselytised policy recommendations.

\section{Theorising sociotechnical transitions: a brief summary of Strategic Niche Management}

The development of the SNM theory coincided and coevolved with that of the multi-level perspective (MLP) model on sociotechnical systems (introduced in Chapter 2), and arguably appears a subset of this larger theory. Much of the SNM literature concerns the early adoption of new technologies that have the potential to contribute to sustainable development goals, with the assumption that innovation journeys can be facilitated by creating and supporting technological niches, protected spaces that allow experimentation (Schot and Geels, 2008). This, in theory, supports new technological pathways capable of penetrating the prevailing regime, destabilising or replacing unsustainable technologies in the process. In focusing on developments at the niche level, SNM presents 'a necessary and reflexive component of intentional transformation processes of regimes', where actors can push new, sustainable technologies on to the market (Kemp et al., 1998, p. 185). Table 13.1 provides an overview of the concept's main features. 


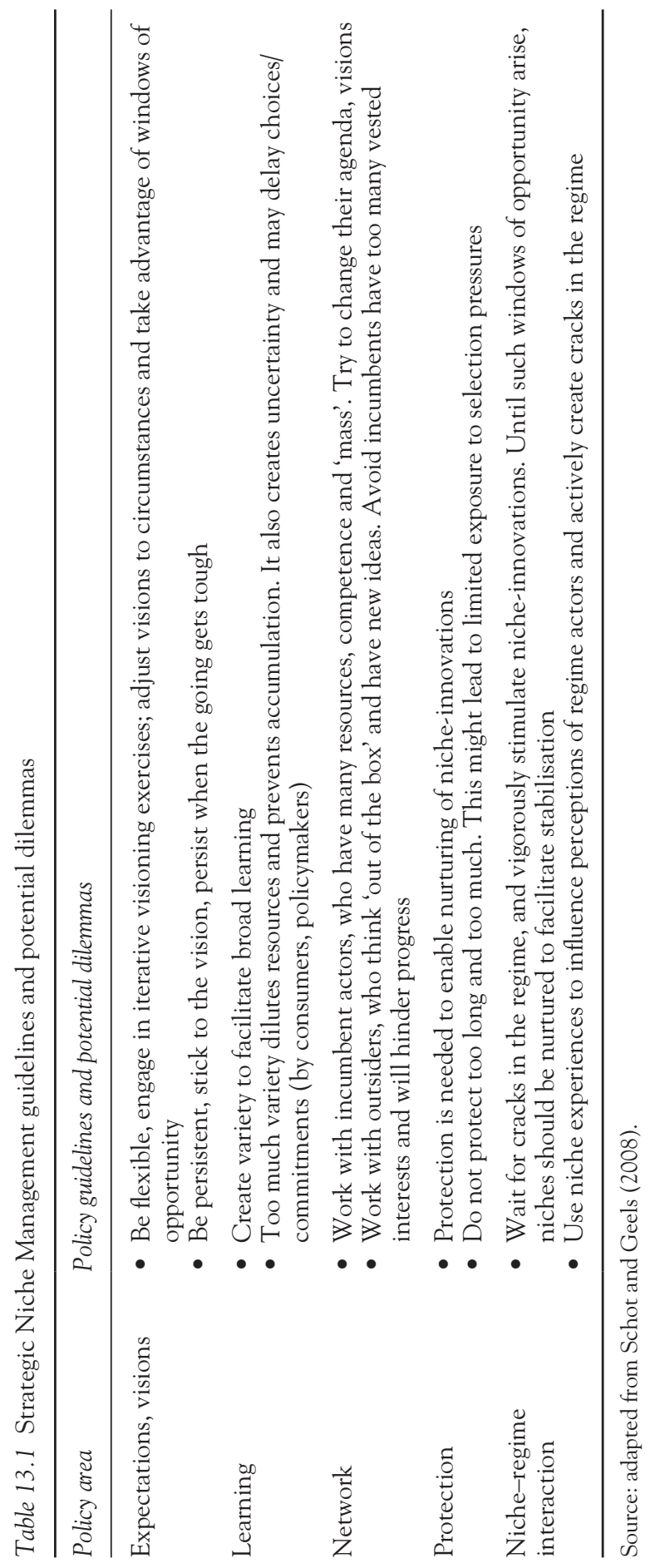


While SNM was initially created as a management tool, in practice, it has also been used as an analytical one. Given that SNM is planned, focused and intended to direct sociotechnical change, it follows that studies investigating or utilising the model should engage with statements on (1) what we are transitioning towards, and (2) how it is possible to achieve this. To this end, we seek to summarise any emergent recommendations from 15 years of research.

\section{Research methods: a systematic review and content analysis}

To collect data for our study, a systematic and extensive search was conducted for peer-reviewed academic, energy-related articles on SNM published between 2002 and 2016, in addition to a complete search of the newsletters of the STRN. We acknowledge from the offset that there are earlier publications in the SNM field not captured by this data range (indeed, some of the most cited emerging in the late 1990s). Nevertheless, we focus on the last 15 years in order to provide a state-of-the-art summary of the most recent developments in the field, building on and corroborating the analysis done by Schot and Geels (2008). Furthermore, we acknowledge that our energy-related sample excludes transitions in other sectors. Yet, given the book is concerned with energy transitions specifically, this segregation is as useful as it is necessary.

For research articles, only those published between 1 January 2002 and 31 December 2016 were collected. To identify relevant articles, the authors searched for the paired terms of 'Strategic Niche Management' and 'energy', 'SNM' and 'electricity', 'SNM' and 'buildings', 'SNM' and 'transport' and 'SNM' and 'vehicles' within three fields, the article title, abstract and keywords. These categories were inclusive, meaning that a single article could not be counted multiple times in different categories, i.e. if they appeared in 'energy' and 'electricity' they would only be coded once. We coded for 'energy' first, meaning that the majority of papers were allocated here - later categories then allowed us to capture ones that would otherwise have been excluded from the sample. These searches were undertaken across nine article databases, resulting in the following sample from each: ScienceDirect (31 papers), JSTOR (0), Project Muse (0), Hein Online (0), SpringerLink (0), Taylor and Francis Online (7), Wiley Online (1), Sage Journals (3) and Annual Reviews (0), selecting only the articles that were peer reviewed, fulllength and written in English.

For the STRN newsletter, we collated all editions published from its establishment in 2011, to the end of 2016 - the latest publication at the time of data collection - and, using the same sampling search criteria as above, sampled from the articles listed in their 'publications' section. Given that these newsletters are designed to explicitly engage with the SNM literature, it was not necessary to select articles based on three fields outlined above, the title, abstract and keywords. This led to the identification of one additional article.

In total, we generated a population of 45 papers. To analyse these resources, we used a content analysis methodology similar to Sovacool (2014). In keeping 
with a contents analysis approach, we primarily focused on quantitative forms of assessment. In all but two instances (see sections headed 'Topics' and 'Policy recommendations' ), categories of analysis were identified before coding began, allowing us to record the articles that met our criteria across those categories only, resulting in a targeted sample that focused on our key questions.

We coded the contents of articles according to ten main categories of analysis; author discipline, author region, author gender, method, case study, topic, attitude towards the speed of transitions, contribution type, analytical strategy and policy recommendations. Each category contained a number of more specific codes, which are outlined in Table 13.2. To determine the coding outcome, coders read the title, abstract and article keywords (when available), before searching the rest of the article for key terms and phases. We recognise that there is some subjectivity inherent in this process. Across all coding categories, basic statistics were then conducted to calculate percentages, frequencies and distribution across years.

Table 13.2 Content analysis coding framework

\begin{tabular}{|c|c|}
\hline Category & Sub-category \\
\hline Author discipline & $\begin{array}{l}\text { Science \& Engineering, Economics \& Statistics; Social Science; } \\
\text { Arts \& Humanities; Interdisciplinary; Other }\end{array}$ \\
\hline Author region & $\begin{array}{l}\text { Africa; Asia-Pacific (including Australia and New Zealand); } \\
\text { Europe (including Russia and Turkey); Latin America and } \\
\text { Caribbean; Middle East; North America } \\
\text { Then each specific country }\end{array}$ \\
\hline Author gender & Male; Female; Indeterminate \\
\hline Method & $\begin{array}{l}\text { Experimental; Surveys; Modelling; Qualitative; Literature } \\
\text { Review; None; Mixed Method }\end{array}$ \\
\hline Case study & $\begin{array}{l}\text { Geographical Case Study; Technological Case Study; If so, } \\
\text { comparative? }\end{array}$ \\
\hline Topic & $\begin{array}{l}\text { Solar; Biofuel; Wave; Wind; Smart Grids; Community Energy; } \\
\text { Energy Efficiency; Zero Energy Buildings; LEDs; Electric Vehicles; } \\
\text { Incumbents; Other; Theoretical }\end{array}$ \\
\hline $\begin{array}{l}\text { Attitude to speed of } \\
\text { transition }\end{array}$ & Negative; Neutral; Optimistic \\
\hline Analytical strategy & Agency; Structure; Meaning \\
\hline $\begin{array}{l}\text { Policy } \\
\text { recommendations }\end{array}$ & $\begin{array}{l}\text { Present; Absent } \\
\text { Financial Support; Regulatory Support; Policy Mixes; } \\
\text { Intermediaries Resourcing; Sectoral Diversity; Diverse } \\
\text { Performance Targets; Mutual Learning; Flexible Institutional } \\
\text { Structure; Brokering and Partnership Management; Private } \\
\text { Sector Empowerment; Evaluation and Feedback; User Training } \\
\text { and Awareness; Standardisation and Licensing }\end{array}$ \\
\hline
\end{tabular}

Source: the authors. 


\section{Author demographics}

We began the content analysis by looking at three categories relating to the demographics of authors: disciplinary affiliation, location and gender. In all categories, we coded for each individual author, not just the lead author. This meant that a paper could receive numerous counts for the same category e.g. two 'female' and one 'male'.

For disciplinary affiliation, we coded the affiliation listed for all paper authors and classified those based on the categories used in Scopus, along with the categories of 'not listed' or 'other'. As authors can list multiple affiliations these categories were inclusive. This meant that an author working under 'management' and 'engineering' would be coded for both 'management' and 'engineering'. Where multiple authors on the paper recorded the same affiliation, it was only coded once. A paper was coded as 'interdisciplinary' if two or more of the authors listed different disciplinary affiliations, if the affiliation itself mentioned more than one discipline e.g. 'Department of Management and Engineering', or if it said 'interdisciplinary' in its title.

For author region, we coded each country listed on the paper. To get an accurate sense of geographical bias, if any, we coded for all paper authors. Where authors listed multiple country affiliations, each one was scored.

Finally, for author gender, authors were coded into 'male', 'female', and 'indeterminate' as some authors only used initials or had names common to both genders.

\section{Methods}

For paper method, we coded for seven categories: 'experimental', 'surveys', 'modelling', 'qualitative', 'literature review', 'none' and 'mixed method'. Articles were only coded for each method listed, meaning they could achieve more than one score. Where more than one method was present, they were determined to be 'mixed method' and further notes were taken. Examples include the presence of semi-structured interviews and documentary analysis, or a documentary analysis, field study and participatory observation.

\section{Case studies}

We coded for whether the articles used geographical case studies (at any scale), technological case studies, or both, and whether these case studies were comparative. Studies were coded as comparative whenever they compared two or more geographical areas or technologies, with further analysis undertaken as to the depth and content of the case study examination. This allowed us to record the scope of the research articles. For papers using geographical case studies, we then coded for which countries they were studying.

\section{Topics}

For this category, our purpose was to discern the general topic of research, rather than to determine the exact nuances of the papers. We began by recording short 
notes on the topic of the article - derived from the title, keywords and abstract, where possible. This included the terms 'incumbents', 'community energy' and 'electric vehicles' for example, as well as a 'theoretical' category. We then inductively built a list of 15 final topics. From these notes, 15 topical themes emerged as summarised in Table 13.2. Each paper was then allocated to all appropriate categories. Papers could be coded in multiple categories i.e. if they referred to both 'smart grids' and 'incumbents'.

\section{Pace of transitions}

We were also interested in attitudes towards the speed of energy transitions, and whether the articles assessed whether it would, could, or should be a fast or a slow process. Articles were coded as 'positive', 'negative' or 'neutral'. Papers were determined to be 'positive' either if they reported potential transitions within ten years or used the term related to a quicker pace, e.g. 'fast', 'rapid', 'quick' or 'accelerated'. 'Neutral' papers either referenced uncertainty over the pace of transitions or gave no comment, including those that did not offer any estimated time in years. Papers were determined to be 'negative' if they stated it would take longer than ten years or used terms such as 'slow', 'long' and 'gradual'.

\section{Analytical strategy}

For analytical strategy, we categorised articles according to whether the publications tended to centre their analytical strategy on 'agency', 'structure' or 'meaning'; in keeping with the classic social theory triangle of agency, structure and meaning - or the three 'I's' of interests, institutions and ideas - that often guide the analysis of analytic strategy and empirical focus (Sovacool and Hess, 2017). We use the term 'centre' to acknowledge that each paper may involve elements of multiple types. Papers coded to the category of 'agency' prioritised the agency of people and their strategies, covering a range of actors, from individuals, organisations and collective groups. 'Structure' refers to macrosocial, infrastructural and institutional hardware; and 'meaning' refers to the cognitive, discursive and normative systems that orient action. For meaning, this implies a focus on language, symbolism, narratives, performativity, and how technologies co-construct and negotiate meaning for human subjects. Most papers were coded to the one category representing their main focus. However, where they explicitly compared two or three theoretical approaches, they were coded in both.

\section{Policy recommendations}

Finally, we coded for policy recommendations by recording information on the suggested recommendations for users, decision-makers, planners, policymakers and regulators in each article. A recommendation was determined to be 


\section{Kirsten E.H. Jenkins and Benjamin K. Sovacool}

'non-academic' when it provided advice or explained lessons for an external stakeholder group, including policymakers and business groups, for example. Coders read the discussion and conclusion and determined whether nonacademic recommendations were either 'present' or 'absent'. When they were present, the relevant information was extracted and then analysed inductively.

\section{Results: unveiling 15 years of Strategic Niche Management research on energy transitions}

This section of the chapter presents the results of the content analysis, following the same structure outlined above.

\section{Author demographics}

Across all articles analysed in the sample, a total of 96 author affiliations were listed, covering a range of disciplines. As panel A of Figure 13.2 shows, authors were strongly associated with social sciences and management disciplines, which made up a total of 74 per cent of the overall sample. The least represented disciples were life sciences and medicine and engineering and technology, which may be unsurprising. Of the papers analysed, only 12 were identified as having interdisciplinary authorship meaning that despite an increasing shift in academic pedagogy towards interdisciplinary research, many authors continue to work in the confines of their own disciplines.

Authors reported affiliations with all global regions, although panel B of Figure 13.1 shows that there was a heavy bias towards European contributions, which made up 82 per cent of the sample. Of those from Europe, 27 per cent were from Dutch authors and 26 per cent were from UK authors. We acknowledge that this is likely related to the availability of research funds in particular countries (as well as, arguably, the origin of the transitions concept itself). It was also possible here to identify recurring authors - (eight papers), Smith (five papers), Seyfang (four), Lovio (four), Hielscher (three), Verbong (three) and Hargreaves (three). This shows not only a geographical limit to the diffusion of this concept, but also an authorial limit. Particularly underrepresented global regions include the Africa ( 1 per cent), Middle East ( 2 per cent) and North America (2 per cent), although we do note that our sample only selected papers written in English from major databases, which may not be readily accessible in some global regions.

For author gender, shown the bottom panel of Figure 13.1, while male contributions did dominate (65 per cent), female authors were fairly well represented at 34 per cent of the total sample. Only 1 per cent of author genders could not be identified. We identify this gender balance as being positive. Sovacool (2014) recognises in his content analysis of 9,549 papers published in the social science research in the energy field, only 15.7 per cent could be identified as female. Although our sample is evidentially significantly smaller, our analysis shows that the SNM literature is currently more gender progressive. 
(A) Author discipline

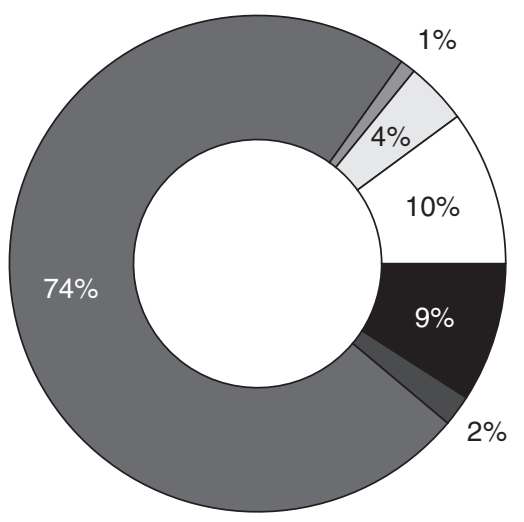

(B) Author region

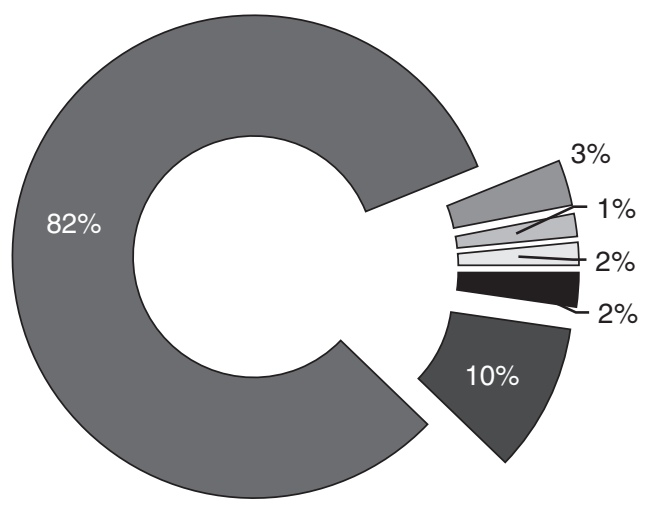

- Engineering and Technology

- Life Science and Medicine

๘ Social Science and Management

$\square$ Arts and Humanities

$\square$ Natural Science

$\square$ Non-academic

$\square$ Not listed/indeterminate
- Africa

Asia-Pacific (inc. AU and NZ)

$\square$ Europe (inc. Russia and Turkey)

uLatin America and Carribean

$\square$ Middle East

$\square$ North America

(C) Author gender

\begin{tabular}{ll}
\hline Gender & Total (\%) \\
\hline Male & 65 \\
Female & 34 \\
Indeterminate & 1 \\
\hline
\end{tabular}

Figure 13.1 Strategic Niche Management author demographics $(\mathrm{n}=100)$. Source: the authors. 


\section{Kirsten E.H. Jenkins and Benjamin K. Sovacool}

\section{Methods}

For methods, shown in the top panel of Figure 13.2, the most favoured approach was secondary data analysis (44 per cent) followed closely by qualitative (43 per cent). The comparative lack of survey (5 per cent), modelling methodologies ( 3 per cent) and experimental ( 0 per cent) methodologies shows new avenues for methodological expansion. Few studies stated no method ( 5 per cent). Of the total papers coded, 35 per cent were identified as being mixed methods studies, primarily relying on a combination of semi-structured interviews and documentary analysis, although with a number of papers also utilised participatory fieldwork including fieldtrips, meeting participation and participant observation. There was methodological diversity throughout the years.

The finding that the top methods employed by SNM researchers are qualitative and dependent on secondary data sources has at least two implications. First, and positively, as qualitative analysis is typically used to explore the socially constructed nature of a phenomenon, the predominance of these methods suggests a focus on the social elements of energy transitions. Whereas Sovacool (2014) identified a need for energy studies research to expand methodologically towards socially sensitive approaches - including the utilisation of more research interviews, field research, focus groups and other human-centred methods of data collection - the SNM literature is, therefore, already stronger in this regard.

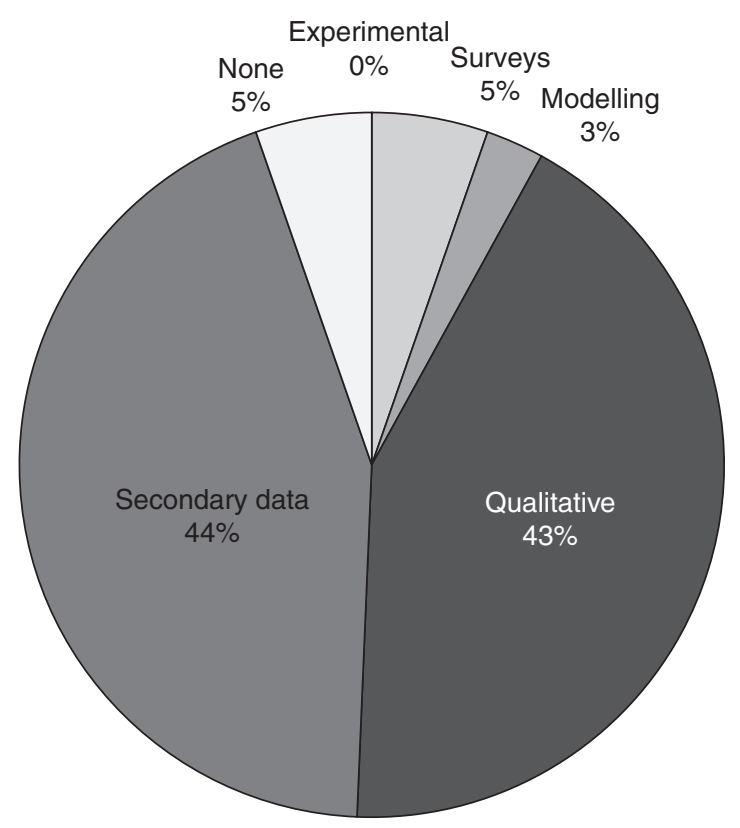

Figure 13.2 Strategic Niche Management article methods $(n=45)$.

Source: the authors. 
Second, as both a positive and a negative, qualitative analyses also give findings that are context specific. Positively, research conclusions and policy recommendations independent of context can be meaningless, thereby context enriches results. Negatively, outside of the presence of multiple cases reinforcing the same results or comparative studies, this hinders the ability for widespread application of the findings and the ability to draw policymaking principles from them. Further, without transparent documentation of the processes undertaken, qualitative analyses can be hard to replicate.

As a result, and drawing on the relative under-emphasis of experimental, survey and modelling methodologies in this sample, we argue for both a continuation of socially oriented methodologies and, crucially, increased attention to modelling techniques and approaches, which may be more testable to statistics, and falsifiable and replicable. The result is findings that may be more readily applicable in practice.

Indeed, a preference for qualitative or literature-based methods ignores experimental designs that have shown great promise across the fields of behavioural science, psychology, and applied sociology (Sorrell 2007; Sovacool and Hess 2017), especially when they investigate scales of social action and actors' roles (Stern et al., 2016). Raven (2005) stated that

SNM can be used for improving the design of experiments, for evaluating policies in the past, for using SNM as part of scenario development, or for designing future policies on niche management. However, SNM has not been used as such in practice, but mainly as a research tool. The policy claims that are often made by SNM researchers still remain a promise; SNM needs real-life experimentation in society.

This is a promise of SNM that remains largely unfilled.

\section{Case studies}

Papers contained a range of both geographical and technological case studies. In the case of geographical case studies, these were not well distributed globally. Few studies utilised examples or analysis of countries or regions in the Global South. Further, most publications were nationally focused, with limited investigations into international commodity systems or international intermediaries such as European Union policymakers. Across all papers analysed, only 16 per cent utilised comparative case studies, whether it was two technologies, two countries or several technologies across different countries. We take this to represent limited engagement with 'lessons learnt' and their application to different international and technological contexts.

There was no clear trend in the countries studied through time. Nonetheless, there was a predominance of SNM scholarship both originating from and using case studies of the United Kingdom and the Netherlands. This indicates a relatively limited scope of global application, empirically supporting the statement 
from Caniëls and Romijn (2008, p. 257) that 'the main preoccupation of the SNM researchers has clearly been on the initiation and management of (individual) experiments', with little consideration for the next stages of market establishment and beyond. Moreover, our finding further reinforces the conclusion of Hoogma et al.'s (2002) book, which has led to substantial research on the local-global distinction between experiments and niches (see Geels and Raven, 2006) as well as spatially informed research on cross-local/transnational dynamics (see Sengers and Raven, 2015).

Indeed, this points to a continued failure to better understand the conditions under which niches, or mainstream alternatives, can truly break through into the wider system (Arranz, 2017). An implication is the need for a greater emphasis on knowledge transfer within the SNM research community, both within academic circles and outside. While innovation niches may first emerge within one country or area - the place where the technology is first designed, piloted or implemented, for example - a technology will not 'break through' into the regime without the supporting impetus to do so. This comes, in part, from widespread geographical diffusion and embedding consistent with a technology or social innovation entering the mainstream marketplace.

\section{Topics}

An article's topic reveals what is considered to be a 'niche' technology or process. Overall, our analysis demonstrated a slight favour for the reporting of energy production niches (43 per cent) as opposed to energy consumption (39 per cent), actors (including intermediaries) (9 per cent) or other (9 per cent). The category 'other' included theoretical contributions and the ideas of Citizen Participation Initiatives (CPI), donor interventions, product-service systems and alternative technology movements, among others. Generally speaking, niche technologies were considered across the full range of the energy system and at both commercial and domestic scales. Although our chapter covers a short time span, Figure 13.3 shows some changes in the popularity of different niche topics. Alongside a general increase in SNM publications throughout the years, there was a clear increase in research on intermediaries, for instance, driven mostly by UK academics including, notably, papers by Seyfang et al. (2014), Hamilton et al. (2014) and Smith et al. (2016).

Moreover, our qualitative coding process did reveal three other topics that occurred with frequency: financial support, mutual learning and brokering. These topics reaffirm and update similar findings and 'conceptual categories' presented by Schot and Geels (2008), where 'learning' and 'networking' were included as key recommendations (although to make the meaning of these categories more transparent, we name them slightly differently). To be specific, 'protection' becomes 'financial support' (including market protection through subsidies and regulation), 'learning' becomes 'mutual learning' and 'networks' becomes 'brokering and partnership management'. Surprisingly given the origins of the literature, there was no clear category relating to expectations/visions. 


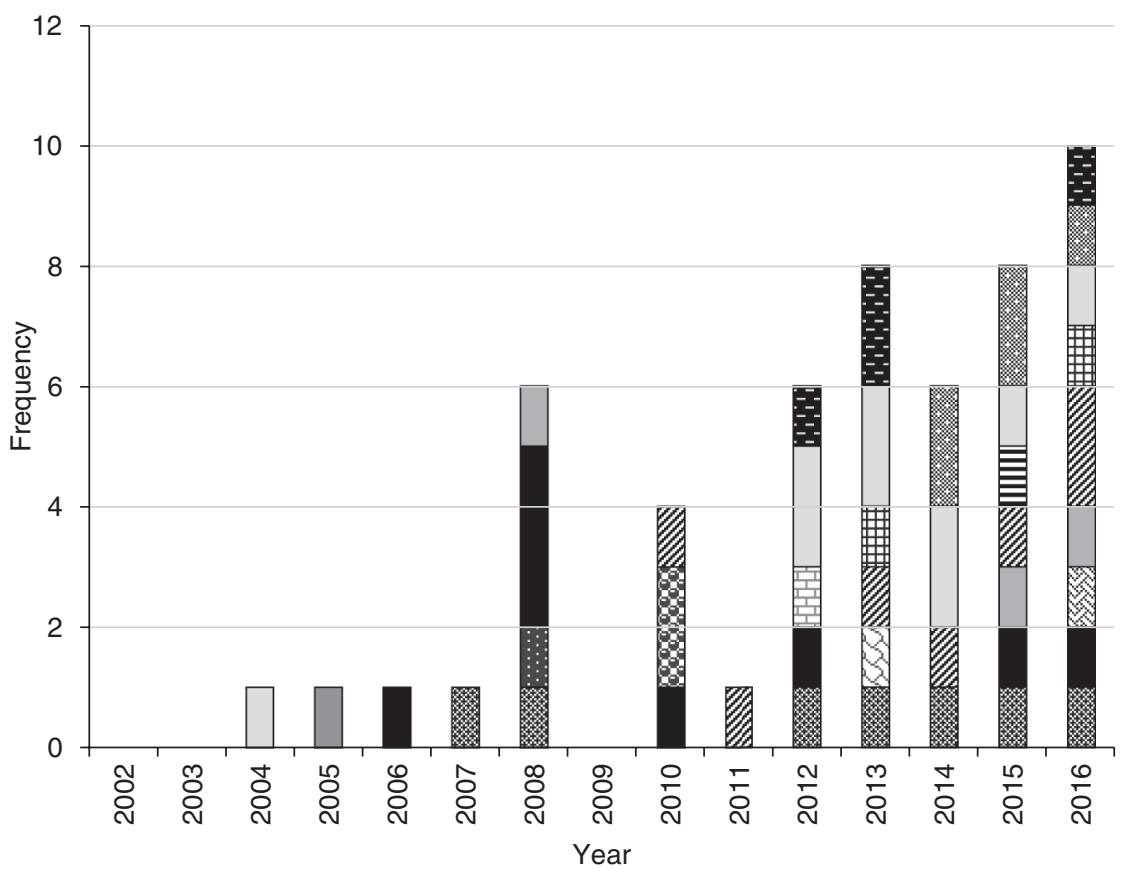

\begin{tabular}{|c|c|c|c|}
\hline Other & 囲 Zero energy buildings & 圆 Energy storage & Hydrogen \\
\hline Intermediaries & 目 Energy efficiency & $\square$ Wind & Solar \\
\hline Electric vehicles & Community energy & 图 Wave & \\
\hline LEDs & Smart grids & Biofuel & \\
\hline
\end{tabular}

Figure 13.3 Distribution of Strategic Niche Management cases by technology $(n=24)$. Source: the authors.

Sixteen of the papers referenced the need for what we term financial support of certain elements of niche innovation. These recommendations manifested as either funding particular intermediary groups or as providing subsidies for niche technologies or taxing others. As an illustration, in the context of smart grid projects, Verbong et al. (2013, p. 123) state 'users are often regarded as a potential barrier to smart grids deployment and financial incentives the best instrument to persuade or seduce the users'. In keeping, Kamp and Forn (2016) referenced that in their case of Ethiopian biogas, entrepreneurial activities were hindered by inadequate financing possibilities. Kamp and Vanheule (2015) explain that improving finance mechanisms will enable end-users to purchase small wind turbines. In all cases, appropriate financing was seen to provide opportunity to remove a barrier and to increase niche diffusion. Steinhilber et al. (2013, p. 537) summarise such recommendations particularly effectively as they write 'governments must therefore find 
the right mix of regulatory pressure and funding options corresponding to the current condition of its national industries and markets, to make innovation attractive for both the supply and demand side'. Thus, in order to manage energy and climate transitions, niches must be appropriately supported fiscally.

Fifteen papers referred to the need for mutual learning, a category that contained notions of face-to-face learning, aggregated knowledge and knowledge exchange, emphasising the social embedding of energy technologies. Seyfang et al. (2014) stress the importance of learning throughout their paper, explaining that in order to strengthen a UK grassroots energy niche, a group of intermediary organisations is needed that has the capacity to consolidate and aggregate the learning and experiences of local projects with a view to repackaging them for implementation elsewhere. This includes learning-by-doing and pro-active learning interactions. As recognition that a community energy niche is heavily grounded in civil society and community engagement, this draws on the social, human and organisational capital alongside and in complement to finance, natural or manufactured capital. Taking a policy focus towards mutual learning, Browne et al. (2012, p. 149), referencing Schwoon (2008), suggest that 'policy-makers should also focus on "technological learning" or "learning-by-doing", which can lead to substantial cost reductions and result in "early mover advantage".

Twelve papers then referred to the topics of brokering and partnership management. Building on the category of mutual learning above, this considered the role of particular groups in directing niche implementation - i.e. who is able to share knowledge. We base the title of this category on the paper by Hargreaves et al. (2013, p. 878), who relay that ideas of 'brokering and partnership management' exist as growing recognition that community energy intermediaries 'can no longer focus solely on internally building local community energy projects but must actively try to work beyond the community energy sector - brokering partnerships and engaging in lobbying activities - to try to shape wider contexts'. This idea is supported in other papers. Kamp and Vanheule (2015, p. 479) add that 'upscaling can be enabled by network expansion through the development of key partnerships with local authorities, financing institutions and local NGOs'. Hamilton et al. (2014) refer to the body responsible for this as a 'moderator' who can convene participatory forums, encourage learning processes and provide leadership, capacity and institutional support with a view to facilitating long-term goals. Importantly, this idea builds on the role of 'intermediation', where certain groups are able to consolidate, grow and diffuse niche innovations. According to Seyfang et al. (2014, p. 40), better-resourced intermediary groups 'could take the initiative in offering resources to new projects, transferring lessons from local projects, liaising with energy utilities and policymakers, and developing standardized models for easier replication'.

\section{Pace of transitions}

In terms of the temporal pace of transitions, the majority of papers either did not give an estimated timespan (47 per cent) or gave a pessimistic or negative 
view (47 per cent) implying that it would either take more than ten years or emphasising qualitatively that transitions processes were long, slow, and cumbersome. Negative statements on timespan typically occurred in reference to economic, institutional and cultural barriers to niche development.

In the few cases where a positive timespan was given ( 6 per cent), it was typically in relation to electric vehicles niches and came with a caveat - that diffusion may appear fast but dispersed, and therefore not necessarily holistic or efficacious. For example, Bakker et al. (2015) exhibit that while quick progress was made for electric vehicle recharging infrastructure, several market movers made different types of electric vehicle plugs, flooding the market and inhibiting the development of a global standard. Thus, 'fast' may not mean effective for the related niche development of electric vehicles. Sushandoyo and Magnusson (2014) illustrate potentially uneven transitions paces as they explored a 20-year timeline for the development of hybrid buses. Their results demonstrated rapid diffusion only towards the end of this range. This shows different pace along with design, diffusion and stabilisation phases of innovation making 'take-off' and the pace of transitions hard to predict.

Such pessimistic framing of transitions does go against some recent empirical evidence highlighting numerous 'fast' transitions that have occurred in both national energy supply and the diffusion of end-use devices (Sovacool, 2016). We note, however, that while market diffusion may sometimes occur quickly, it often only results after decades of pre-development. Rotmans et al. (2001) support this idea as they note that transitions may appear to be quick, even when their pre-development is long. This phase - also known as the valley of death - is, in many ways, what the SNM literature has been developed to understand. Nevertheless, with conscious of the real path dependencies and lock-ins in incumbent regimes, we refer here, to the need for positivity and practically oriented forward thinking about the potential of energy transitions.

\section{Analytical strategy}

When coding for analytical strategy, there was a slight dominance of papers in the 'agency' category ( 55 per cent), followed by 'structure' (36 per cent) and 'meaning' (9 per cent). While one paper did engage with all three approaches (Caniëls and Romijn, 2008), this was a literature review. Reflecting this, papers discussed a range of actors, from individuals and organisations to collective groups. This included, most notably, a strong focus on community energy groups and intermediaries as drivers and enablers of energy transitions. Given the planned nature of SNM outlined above, and indeed, the focus on 'management' within the approach in general, this focus on agency was determined as necessary and unsurprising as we consider who manages transitions or is affected by them. Nonetheless, analytical strategies emphasising agency can assume that people are atomistic agents whose action can be explained without deep consideration of structure (Jackson, 2005). Indeed, Mouzelis (1995) warns that the micro-turn in social theory towards agency has led to an almost complete 
neglect of asking questions about bigger entities, reification, or the structural or functional attributes of larger systems.

In our sample, the almost complete emphasis within the SNM literature on only agency and structure - and not meaning - implies a failure to appreciate the power of language, symbolism, narratives, performativity, rhetorical visions, and how technologies can co-construct and negotiate meaning for human subjects (although this was touched upon briefly in some instances e.g. through Verbong et al.'s (2008) statements on expectations and visions). This absence of papers considering the meaning category will be surprising to some, given the potential argument that SNM was built upon science and technology studies with a particular emphasis on the dynamics of expectations as one way of giving meaning to the (future) world.

In this vein, we note that it may be possible to analyse and explore how (and why) the SNM research has been guided to an overemphasis of agency and structure at the expense of meaning. Indeed, it seems fruitful for the SNM community to continue to engage with relational theories that emphasise agency, structure and meaning together. Such approaches may emphasise social relations and interactions, but they also highlight the webs of social structure and meaning in which actors are suspended and which they change through their action (Geels, 2009; Rutherford and Coutard, 2014). We say 'continue to engage' as acknowledgement that although relational perspectives on niche development can be developed in more detail, they do already exist.

At least four papers in the sample seemed to recognise the value of a processual approach, or at least combined different analytical strategies. Hatzl et al.'s (2016, p. 58) paper explained the typical distinction between (a) grassroots social innovation and (b) market-based technological innovations, representing an 'agency' vs. 'structure' split. In their work they argued that CPIs for niche developments, represented 'a continuum from market-based to grassroots characteristics in order to facilitate a more detailed picture of niche development'. Here, social arrangements such as CPIs are both ideologically motivated but also show market-based characteristics such as profit seeking.

\section{Policy recommendations}

Across the entire sample of SNM literature, 56 per cent of papers contained explicit policy recommendations, leaving 44 per cent without non-academic impact statements. In terms of type and scope of recommendations, financial support $(n=16)$; regulatory support $(n=4)$; policy mixes $(n=4)$; intermediaries resourcing $(n=3)$; sectoral diversity $(n=4)$; diverse performance targets $(n=3)$; mutual learning $(n=15)$; flexible institutional structure $(n=3)$; brokering and partnership management $(n=12)$; private sector empowerment $(n=3)$, evaluation and feedback $(n=4)$, user training and awareness $(n=1)$ and standardisation and licensing $(n=3)$ were suggested repeatedly. Table 13.3 provides one indicative recommendation for each of the categories listed above. These ideas are then further explored in the conclusion. 


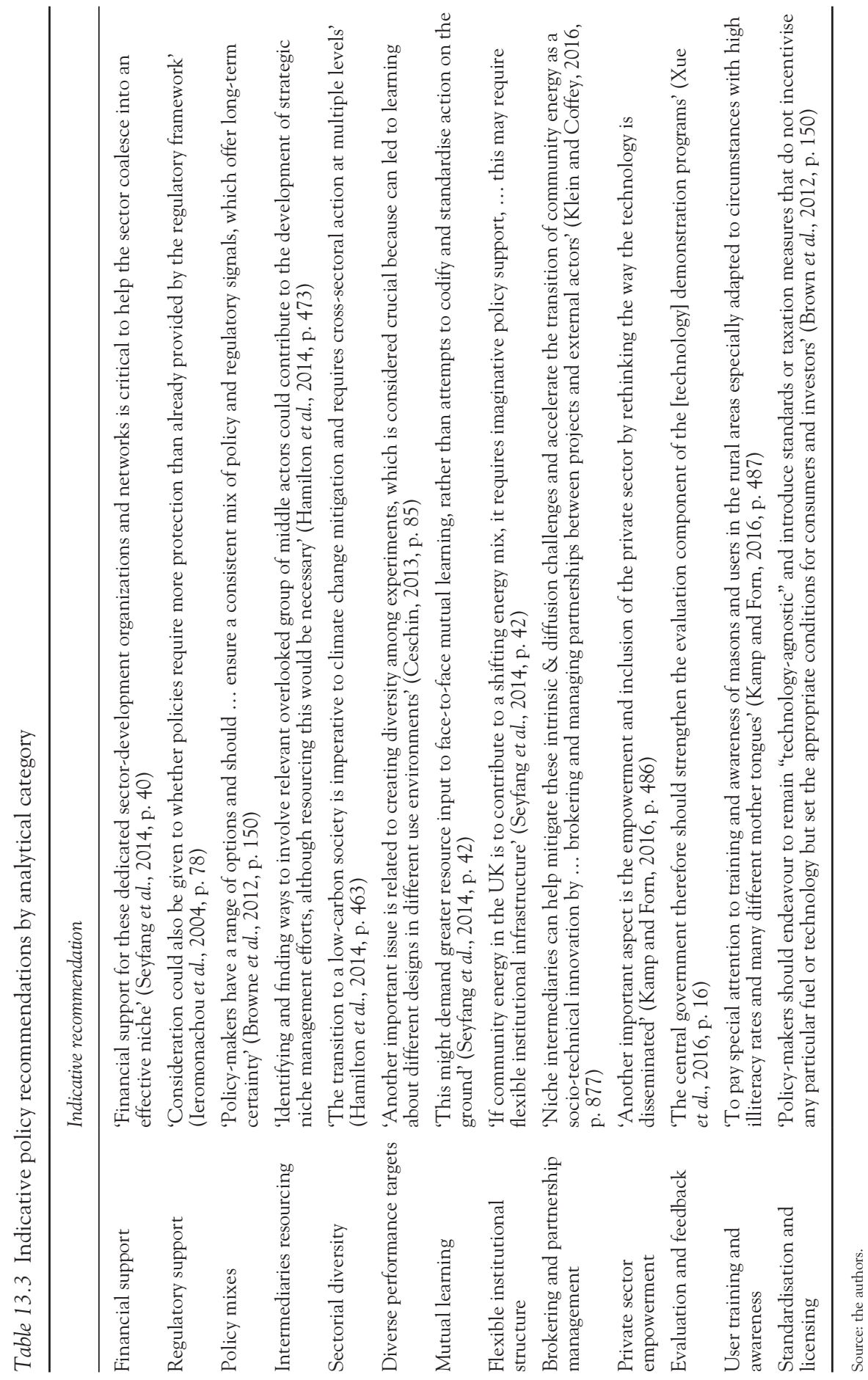


Interestingly, recommendations were given for both government policymakers, local authorities and specific technology user groups, including industry members and intermediaries. Kamp and Vanheule (2015, p. 497) stated to this end that 'niche upscaling is not solely in the hands of the government. Rather than standing aside, technology supplies, research institutes and NGOs can enable change themselves with targeted and joint efforts'. In this regard, the range of non-academic stakeholders deemed to be of relevance was wide.

Moreover, where recommendations were present, they contained a diverse array of suggestions, ranging from both directly implementable options to broader policymaking principles (and even, in one instance, recommendations to avoid biofuel crop monoculture (Eijck and Romijn, 2008)). As illustrated in Table 13.3, this includes a distinction between technocratic solutions - e.g. technology standardisation and licensing (e.g. Kamp and Vanheule, 2015) - and socially oriented user-based engagement (e.g. Hargreaves et al., 2013), where Raven et al. (2008, p. 475) identified that ultimately, 'ready-made solutions cannot be dropped into a context without local negotiations'. Fitting the socially oriented recommendations category, Seyfang et al. (2014, p. 42) advocated for 'imaginative policy' support before going on to suggest what this might look like, including steers towards flexible institutional infrastructure. Browne et al. (2012, p. 150) outlined a clear series of recommendations that crossed these two categories, where they advised that policymakers should consider:

1 developing a transition strategy and engaging in scenario planning with industry stakeholders;

2 identifying potential 'lead adopters' and develop a strategy for SNM;

3 developing stakeholder partnerships with industry and consumer groups;

4 promoting the adoption of new sociotechnical regimes through awareness campaigns and education;

5 changing the taxation structure to tax negative externalities and create positive incentives through excise relief and subsidies;

6 providing long-term certainty through a constant mix of policy and regulatory signals.

A further strong example was provided by Tsoutsos and Stamboulis (2005) who, in a standalone section, suggest three key policy aims: (1) the development of focused learning mechanisms, (2) the encouragement of new types of players and 3) flexible financing mechanisms, adapted to the characteristics of individual applications and environmentally consistent academic evaluation.

Some studies introduced a 'mutual learning' category to encompass suggestions for creating individual groups responsible for knowledge sharing or increased education across the full range of relevant stakeholders (e.g. Kamp and Vanheule, 2015). Sushandoyo and Magnusson (2012) argue that this should include provision of information on internal synergies, scale economies and projections of future sales and production volumes in the case of developing 
technologies. Verbong et al. (2008) identified the need for clearly expressed expectations and visions at the beginning of and during niche transformations.

Admittedly, although our analysis does not reveal the degree to which SNM findings and approaches are integrated in practice, it does illustrate the range of potential options for doing so. This diversity of potential policy options can be perceived as strength as it illustrates a range of different tools that can be applied in different contexts, plus the ability to tailor solutions. However, more work is needed that looks at exactly how, if and where policy lessons have been applied as attempts to and lessons from translating them into actual politics have not been well documented. Stemming from our analysis, we suggest that one fruitful avenue would be to look at the politics behind the policies, creating coalitions of stakeholders, so that low-carbon transitions occur.

\section{Conclusions and policy recommendations}

Our systematic review of the literature has exposed both trends and gaps in the SNM literature and importantly, summarised key recommendation for transitions management. With this in mind, we offer four key findings and conclusions.

First, there is an intellectual diversity within the transitions management community that we laud. Our review has demonstrated some positive demographic trends within authors. We have found contributions from across many academic disciplines, a fair balance of male and female contributors to the literature, a diversity of methods applied variously and analytical strategies that focus on the social integration and fostering of innovations, including concerns for energy groups and intermediaries. The recent SNM literature engaged with a range of geographical and technological cases, with studies primarily focusing on the UK and the Netherlands, but also with less typical case studies of China, India, Ethiopia and Malaysia. Cumulatively across the sample years, the top three technological case studies included solar energy, biofuels and electric vehicles.

Second, we identify positive qualitative or topical trends within the community. There is a commitment to technological agnosticism, illustrated by a range of technological and geographical cases used within papers. There also appears to be a ready commitment to policy engagement, in that that a majority of publications analysed (56 per cent) provide a series of non-academic recommendations stemming from empirical and theoretical work. These recommendations were targeted at government officials, industry members and intermediaries, among others, showing wide application and relevance. The most frequently reoccurring recommendations or topics focused on (1) the appropriate financing of niche innovations, (2) mutual learning between stakeholders and across niches, and (3) brokering and partnership in order to strengthen niche development. As a key contribution of this chapter in line with the policy focus of the book it sits within, focusing on these areas increases our ability to manage energy and climate transitions. 


\section{Kirsten E.H. Jenkins and Benjamin K. Sovacool}

Third, there were also worrying demographic trends related to geographic and methodological bias. There was a heavy bias towards European authorship, which contributed 82 per cent of the sample (with 26 per cent from UK authors and 27 per cent from Dutch authors). In addition, geographic case studies are not well distributed globally with few studies in the Global South and most publications taking on national case studies, with limited investigations into international commodity systems or international intermediaries. Further, while positive in some regards, the predominance of qualitative and secondary data methodologies has downsides as well. This methodical focus leads to results that may be hard to replicate and, in many cases, and context specific, with knockons for the ability for widespread application of the findings and the ability to draw policymaking principles from them. Experimental research designs have also been largely avoided by the SNM community.

On the grounds of these failings, we make recommendations for future research and policy-oriented commitments. It follows that our recommendation is to improve this negative demographic trend is for greater emphasis to be placed not only on increasing the breadth of case studies but also on comparing them. Doing so could aid the identification of more generalisable or scalable lessons or policy principles. Moreover, we appeal for broader methods, capable of capturing a broader range of perspectives on the challenges we face and most pressingly, their solutions.

Finally, and also critically, there was an apparent inability to draw comparative lessons either across technologies or countries within the SNM literature, and in some cases, where they were absent, engage with non-academic impact statements. These failures have at least three consequences. First, a failure to translate information between countries may leave niches isolated, preventing mainstream adoption. Second, a failure to compare technologies restricts lesson learning, therefore increasing the probability of negative mistakes. As demonstrated by Bakker et al. (2015), it also inhibits the development of a global standard technology that, through pervasive uptake, can challenge regime technologies. Third, a failure to engage with non-academic impact statements represents, in essence, a failure to maximise the discursive potential of academic research. It follows that we call for more synthesis across the literature and further attempts to take academic discussion towards practical implementation. We have identified a conservative and pessimistic approach to envisioning the timing, temporal pace or accelerative potential of low-carbon energy transitions within the SNM literature as well. We wonder if the very hesitancy from SNM theorists to validate the notion of expedient transitions, and the continued dominance of techno-economic analyses rooted in modelling, contributes in part to the very 'lock-in' or 'path dependency' they critique. The theorists endow the fossil fuel regime with perhaps more agency than it actually has or need have. The point being that the very discourse we in the academy utilise to frame and engage on energy and carbon transitions can distort and even reinforce trends in that very empirical space. 


\section{References}

Arranz, A.M. (2017) Lessons from the past for sustainability transitions? A meta-analysis of socio-technical studies. Global Environmental Change 44: 125-143.

Bakker, S., Leguijt, P. and van Lente, H. (2015) Niche accumulation and standardization the case of electric vehicle recharging plugs. Journal of Cleaner Production 94: 155-164.

Bergek, A., Jacobsson, S., Carlsson, B., Lindmark, S. and Rickne, A. (2008) Analysing the functional dynamics of technological innovation systems: A scheme of analysis. Research Policy 37(3): 407-429.

Browne, D., O'Mahony, M. and Caulfield, B. (2012) How should barriers to alternative fuels and vehicles be classified and potential policies to promote innovative technologies be evaluated. Journal of Cleaner Production 35: 140-151.

Caniëls, M.C.J. and Romijn, H.A. (2008) Actor networks in strategic niche management: insights from social network theory. Futures 40(7): 613-629.

Ceschin, F. (2013) Critical factors for implementing and diffusing sustainable productService systems: Insights from innovation studies and companies' experiences. Journal of Cleaner Production 45: 74-88.

Eijck, van J. and Romijn, H. (2007) Prospects for Jatropha biofuels in Tanzania: An analysis with Strategic Niche Management. Energy Policy 36(1): 311-325.

Geels, F.W. (2009) Foundational ontologies and multi-paradigm analysis, applied to the socio-technical transition from mixed farming to intensive pig husbandry (1930-1980). Technology Analysis and Strategic Management 21(7): 805-832.

Geels, F.W. (2014) Regime resistance against low-carbon transitions: Introducing politics and power into the multi-level perspective. Theory, Culture and Society 31(5): 21-40.

Geels, F.W. and Raven, R. (2006) Non-linearity and expectations in niche-development trajectories: Ups and downs in Dutch biogas development (1973-2003). Technology Analysis and Strategic Management 18(3-4): 375-392.

Geels, F.W., Sovacool, B.K., Schwanen, T., Sorrell, S. (2017) Sociotechnical transitions for deep decarbonisation. Science 357(6357): 1242-1244.

Grubler, A., Wilson, C. and Nemet, G. (2016) Apples, oranges, and consistent comparisons of the temporal dynamics of energy transitions. Energy Research and Social Science 22: $18-25$.

Hamilton, J., Mayne, R., Parag, Y. and Bergman, N. (2014) Scaling up local carbon action: The role of partnerships, networks and policy. Carbon Management 5(4): 463-476.

Hargreaves, T., Hielscher, S., Seyfang, G. and Smith, A. (2013) Grassroot innovations in community energy: The role of intermediaries in niche development. Global Environmental Change 23(5): 868-880.

Hatzl, S., Seebauer, S., Fleiß, E. and Posch, A. (2016) Market-based vs. grassroots citizen participation initiatives in photovoltaics: A qualitative comparison of niche development. Futures 78-79: 57-70.

Hoogma, R., Kemp, R., Schot, J. and Truffer, B. (2002) Experimenting for Sustainable Transport. The Approach of Strategic Niche Management. Routledge, London, UK.

Ieromonachou, P., Potter, S. and Enoch, M. (2004) Adapting strategic niche management for evaluating radical transport policies-the chase of Durham Road access charging scheme. International Journal of Transport Management 2(2): 75-87.

International Renewable Energy Agency and International Energy Agency (2017) Perspectives for the Energy Transition: Investment Needs for a Low-carbon Energy System. Available at: www.irena.org/menu/index.aspx?mnu=Subcat\&PriMenuID=36 $\&$ CatID=141\&SubcatID=3828. 


\section{Kirsten E.H. Jenkins and Benjamin K. Sovacool}

Jackson, T. (2005) Motivating Sustainable Consumption: A Review of Evidence on Consumer Behaviour and Behavioural Change. A Report to the Sustainable Development Research Network. Sustainable Development Research Network, Surrey, UK. Available at: www.sustainablelifestyles.ac.uk/sites/default/files/motivating_sc_final.pdf.

Jain, M., Hoppe, T. and Bressers, H. (2016) Analyzing sectoral niche formation: The case of net-zero energy buildings in India. Environmental Innovation and Societal Transitions 25: 47-63.

Kamp, L.M. and Forn, E.B. (2016) Ethiopia's emerging domestic biogas sector: Current status, bottlenecks and drivers. Renewable and Sustainable Energy Reviews 60: 475-488.

Kamp, L.M. and Vanheule, L.F.I. (2015) Review of small wind turbine sector in Kenya: Status and bottlenecks for growth. Renewable and Sustainable Energy Reviews 49: 470-480.

Kemp, R., Schot, J. and Hoogma, R. (1998) Regime shifts to sustainability through processes of niche formation: The approach of strategic niche management. Technology Analysis and Strategic Management 10(2): 175-198.

Klein, S.J.W. and Coffey, S. (2016) Building a sustainable energy future, one community at a time. Renewable and Sustainable Energy Reviews 60: 867-880.

Lovell, H. (2007) The governance of innovation in socio-technical systems: The difficulties of strategic niche management in practice. Science and Public Policy 34(1): 35-44.

Markard, J., Raven, R. and Truffer, B. (2012) Sustainability transitions: An emerging field of research and its prospects. Research Policy 41(6): 955-967.

Martiskainen, M. and Kivimaa, P. (2018) Creating innovative zero carbon homes in the United Kingdom - intermediaries and champions in building projects. Environmental Innovation and Societal Transitions 26: 15-31.

Mouzelis, N. (1995) Sociological Theory: What Went Wrong? Diagnoses and Remedies. Routledge, London, UK.

Raven, R.P.J.M. (2005) Strategic niche management for biomass: A comparative study on the experimental introduction of bioenergy technologies in the Netherlands and Denmark. PhD Thesis. Technische Universiteit Eindhoven.

Raven, R.P.J.M., Heiskanen, E., Lovio, R., Hodson, M. and Brohmann, B. (2008) The contribution of local experiments and negotiation processes to field-level learning in emerging (niche) technologies: Meta-analysis of 27 new energy projects in Europe. Bulletin of Science, Technology and Society 28(6): 464-477.

Rotmans, J., Kemp, R. and Van Asselt, M. (2001) More evolution than revolution: Transition management in public policy. Foresight 3: 15-31.

Rutherford, J. and Coutard, O. (2014) Urban energy transitions: Places, processes and politics of socio-technical change. Urban Studies 51(7): 1353-1377.

Schot, J.W. and Geels, F.W. (2008) Strategic niche management and sustainable innovation journeys: Theory, findings, research agenda, and policy. Technology Analysis and Strategic Management 20(5): 537-554.

Schwoon, M. (2008) Learning by doing, learning spillovers and the diffusion of fuel cell vehicles. Simulation Modelling Practice and Theory 16(9): 1463-1476.

Sengers, F. and Raven, R. (2015) Towards a spatial perspective on niche development: The case of bus rapid transit. Environmental Innovation and Societal Transitions 17: 166-182.

Seyfang, G., Hielscher, S., Hargreaves, T., Martiskainen, M. and Smith, A. (2014) A grassroots sustainable energy niche? Reflections on community energy in the UK. Environmental Innovation and Societal Transitions 13: 21-44.

Smith, A., Hargreaves, T., Hielscher, S., Martiskainen, M. and Seyfang, G. (2016) Making the most of community energies: Three perspectives on grassroots innovation. Environment and Planning A 48(2): 407-432. 
Sorrell, S. (2007) Improving the evidence base for energy policy: The role of systematic reviews, Energy Policy 35(3): 1858-1871.

Sovacool, B.K. (2014) What are we doing here? Analysing 15 years of energy scholarship and proposing a social science research agenda. Energy Research and Social Science 1: 1-29.

Sovacool, B.K. (2016) How long will it take? Conceptualizing the temporal dynamics of energy transitions, Energy Research Eु Social Science 13: 202-215.

Sovacool, B.K. (2017) Experts, theories, and electric mobility transitions: Toward an integrated conceptual framework for the adoption of electric vehicles. Energy Research and Social Science 27: 78-95.

Sovacool, B.K. and Hess, D.J. (2017) Ordering theories: Typologies and conceptual frameworks for sociotechnical change. Social Studies of Science 7(5): 703-750. DOI: 10.1177/0306312717709363.

Steinhilber, S., Wells, P. and Thankappan, S. (2013) Socio-technical inertia: Understanding the barriers to electric vehicles. Energy Policy 60: 531-539.

Stern, P.C., Sovacool, B.K. and Dietz, T. (2016) Towards a science of climate and energy choices. Nature Climate Change 6: 547-555.

Sushandoyo, D. and Magnusson, T. (2014) Strategic niche management from a business perspective: Taking cleaner vehicle technologies from prototype to series production, Journal of Cleaner Production 74(1): 17-26.

Tsoutsos, T.D. and Stamboulis, Y.A. (2005) The sustainable diffusion of renewable energy technologies as an example of an innovation-focused policy. Technovation 25(7): 753-761.

Van den Bergh, J.C.J.M., Truffer, B. and Kallis, G. (2011) Environmental innovation and societal transitions: Introduction and overview. Environmental Innovations and Societal Transitions 1(1): 1-23.

Van der Laak, W.W.M, Raven, R.P.J.M. and Verbong, G.P.J. (2007) Strategic niche management for biofuels: Analysing past experiments for developing new biofuel policies. Energy Policy 35(6): 3213-3255.

Verbong, G.P.J., Beemsterboer, S. and Senger, F. (2013) Smart grids or smart users? Involving users in developing a low carbon electricity economy. Energy Policy 52: 117-125.

Verbong, G.P.J., Christiaens, W., Raven, R. and Balkema, A. (2010) Strategic niche management in an unstable regime: Biomass gasification in India. Environmental Science and Policy 12(4): 272-281.

Verbong, G., Geels, F.W. and Raven, R. (2008) Multi-niche analysis of dynamics and policies in Dutch renewable energy innovation journeys (1970-2006): Hype-cycles, closed networks and technology-focused learning. Technology Analysis and Strategic Management 20(5): 555-573.

Weber, M., Hoogma, R. Lane, B. and Schot, J. (1999) Experimenting with Sustainable Transport Innovations: A Workbook for Strategic Niche Management. University of Twente, Seville/Enschede.

Xue, Y., You, J., Liang, X. and Liu, H-C. (2016). Adopting strategic niche management to evaluate EV demonstration projects in China. Sustainability 8(2): 142. DOI: $10.3390 /$ su8020142. 


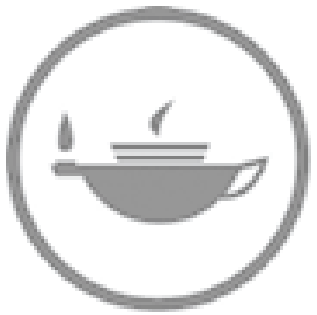

Taylor \& Francis Taylor \& Francis Group

http://taylorandfrancis.com 